\title{
CONTO "NEGRINHA” À LUZ DO LETRAMENTO CRÍTICO: UMA EXPERIÊNCIA SOBRE IDENTIDADE NO PROJETO MAIS EDUCAÇÃO
}

\author{
THE TALE "NEGRINHA" UNDER THE LIGHT OF CRITICAL LITERACY: AN EXPERIENCE \\ ON IDENTITY IN THE PROJECT "MAIS EDUCAÇÃO"
}

Jéssica Gonçalves da SILVA Universidade do Estado do Rio de Janeiro jessicaqdasilva91@yahoo.com.br

Ana Carolina da Conceição FIGUEIREDO Universidade do Estado do Rio de Janeiro karolfigueiredo@hotmail.com

Kátia Nazareth Moura de ABREU Universidade do Estado do Rio de Janeiro kabreu00@gmail.com

Resumo: O presente artigo é fruto de uma atividade pedagógica sobre o racismo por meio da leitura crítica e de atividades de compreensão e intervenção em um contexto escolar do Projeto Mais Educação desenvolvido na cidade de Maricá, situada no Estado do Rio de Janeiro. Essa atividade foi realizada em uma escola estadual em uma turma do ensino fundamental II, com o intuito de estimular a leitura crítica do texto literário Negrinha de Monteiro Lobato. A abordagem do estudo tem como fundamento teórico e metodológico as concepções de leitura e escrita no viés do letramento crítico de Freire (1989), Gee (1996), Green (1998), Kalantzis e Cope (2012) e do princípio de que não há nenhum discurso neutro, ou seja, todo texto possui condicionantes sociais, daí a importância de se "desenvolver caminhos para ver de onde eles vêm e reconhecer como são designados por nós, leitores" (JANKS, 2016). Além disso, alinhamo-nos com o pensamento teórico de JAUSS (1994), teórico da Teoria da Estética da Recepção, ao compreendermos que a leitura resulta na fusão do horizonte de expectativa do leitor/aluno com o horizonte de expectativa do texto. O objetivo deste artigo é tecer reflexões sobre a importância do letramento crítico na prática escolar.

Palavras-chave: Racismo. Letramento crítico. Identidade. Negrinha.

Abstract: This article presents the findings of a pedagogical activity about racism through critical reading and activities of comprehension and intervention developed in a school context of the project "Mais Educação" developed in the city of Maricá, located in the State of Rio de Janeiro (Brazil). This activity was developed in a middle school class of a public school, with the aim of stimulating the critical reading of the literary text Negrinha written by Monteiro Lobato. Both 
theoretical and methodological foundations were based on the studies addressing critical literacy realized by Freire (1989), Gee (1996), Green (1998), Kalantzis and Cope (2012) and from the principle that there is no neutral discourse, i.e., every text has social constraints and that is why "developing paths to see where they come from and recognize how they are designated by us, readers" (JANKS, 2016) In addition, we are aligned with the theoretical thought of JAUSS (1994), theoretician of the Aesthetics of Reception Theory, to understand that reading is a result from the fusion of horizon of the expectation of the reader/student with the horizon of expectation of the text. The objective of this article is making reflections about the importance of critical literacy in pedagogical technique.

Keywords: Racism. Critical literacy. Identity. Negrinha.

\section{Introdução}

Em uma proposta de ensino baseada na perspectiva do letramento crítico, o processo de ensino-aprendizagem pode gerar a prática participativa dos alunos de forma democrática e contribuir para a autorreflexão dos discentes, os quais são também sujeitos do ato de conhecimento. Essa prática dos alunos em participarem criticamente da leitura do mundo é desenvolvida também pela ação de pensar a própria atitude. Ou seja, a consciência crítica das suas próprias práticas no mundo.

Assim, a atividade desenvolvida e que toma lugar aqui visa a formação de cidadãos críticos e conscientes a partir da interação promovida em sala de aula, com destaque para a ampliação da percepção sobre diversos assuntos. Afinal, não nos escapa que habilidades de letramento avançadas são requisitos do mundo contemporâneo e isto inclui a capacidade de pensar criticamente que começa na contextualização passa pela análise indo até a interação inter e extra comunidade (Brydon, 2011).

Pensando dessa forma, nosso objeto de análise consiste na produção textual sobre a temática do racismo que foi desenvolvida em uma turma do projeto Mais Educação de um colégio estadual situado no município de Maricá/Rio de Janeiro, com o objetivo de refletir sobre a leitura como um processo de comunicação interacional crítica, a fim de pensar como ocorreu o envolvimento do aluno com o texto literário, tendo em vista que os textos, de forma geral, veiculam ideologias e princípios e poderão exercer um papel de disseminador pedagógico. Os alunos que participaram dessa atividade de leitura 
frequentam anos variados do Ensino Fundamental II: 7은 $8^{\circ}$ e $9^{\circ}$ ano. Esse trabalho de leitura, desenvolvido ao longo do período letivo, perpassou temáticas variadas desde relacionamentos, machismo até discussões relacionadas ao feminismo e à intolerância racial, tema selecionado para esse artigo.

Ao discutirmos o tema da intolerância racial, a partir do conto Negrinha de Monteiro Lobato, consideramos toda a bagagem de leitura que os alunos possuem e levam para o texto. Compreendemos conforme Hans Robert Jauss (1994), teórico da Estética da Recepção, que o leitor/aluno tem um horizonte de expectativa, vivências de mundo, experiências pessoais, um olhar histórico e social, conhecimentos linguísticos e literários. Desse modo, durante a leitura, todo esse repertório do aluno é acionado para que ele compreenda o texto e é possível notar que as verdades ou mentiras que são construídas a partir do texto são interpretações derivadas da percepção do leitor/aluno.

Organizamos o presente artigo do seguinte modo: apresentamos na introdução o objetivo da pesquisa e a justificativa de sua relevância para as pesquisas sobre letramento crítico. $\mathrm{Na}$ segunda seção, apresentamos a fundamentação teórica. A terceira seção do artigo contextualiza o ambiente da pesquisa e a metodologia utilizada. Na seção 4 realizamos a interpretação dos dados, fundamentada na literatura selecionada. $\mathrm{Na}$ seção 5 , seguem as considerações finais.

Em todo esse percurso procuramos não perder de vista a relevância do conceito de letramento crítico associado à ideia de "capacidade" do sujeito para que este possa por meio da linguagem atuar em práticas sociais diversificadas, posicionando-se como sujeito crítico e, por fim, provocando as mudanças que deseja.

\section{Fundamentação teórica}

O pressuposto teórico e metodológico que norteia este trabalho está embasado na proposta freiriana de leitura do mundo. Para Freire (1989), a compreensão crítica do ato de ler está diretamente relacionada com a leitura do mundo, ou seja, esta sempre precede a leitura da palavra. A leitura do mundo 
implica a continuidade da leitura da palavra, ou seja, estão dinamicamente juntas.

Freire (1989, p. 20) afirma que "a leitura da palavra não é apenas precedida pela leitura do mundo mas por uma certa forma de "escrevê-lo" ou de "reescrevêlo", através de um movimento dinâmico.

Freire (1989) também propõe que os educandos escrevam e leiam praticando a escrita e a leitura. Para o autor, não é possível escrever sem que haja a prática da escrita. No quesito compreensão textual e leitura crítica, Freire afirma que o ato de alcançar a compreensão do texto através de sua leitura crítica implica perceber as relações entre o texto e o contexto. Sendo assim, aprender a ler e a escrever, é aprender a ler o mundo e a compreender o seu contexto, através da relação dinâmica entre linguagem e realidade. Para entender a relação entre leitura do mundo e leitura da palavra, é preciso compreender a palavra escrita, a linguagem, assim como as suas relações com o contexto de quem fala e de quem lê e escreve.

Nesta perspectiva, a leitura e a escrita não são vistas como atividades dicotômicas, mas sim como processos inseparáveis através da compreensão e do domínio da língua e da linguagem. O processo do ato de ler, implica sempre o entendimento crítico, a interpretação e "re-escrita" do que foi lido. Sendo assim, através do ensino democrático e crítico, a leitura da palavra e a leitura do mundo estão dinamicamente coadunadas. A prática da leitura e da escrita a partir de palavras e temas relevantes ao contexto escolar dos educandos pode contribuir para a leitura do real. Já o ensino na perspectiva da memorização e da manipulação mecânica de palavras toma a leitura como pura descrição do objeto, não possibilitando que os aprendizes conheçam a constituição do texto e nem façam a sua leitura real, não permitindo o letramento crítico.

Pensar a prática de leitura pela perspectiva do letramento crítico consiste em refletir sobre um trabalho de leitura com foco no envolvimento do aluno/leitor com o texto, tendo em vista que, ambos atuam no desenrolar da constituição de sentido. Nesse sentido, Jouve (2002, p.61) postula que "saber como se lê é determinar a parte respectiva do texto e do leitor na concretização do sentido. $A$ 
leitura, de fato, longe de ser uma recepção passiva, apresenta-se como uma interação entre o texto e o leitor".

Durante o percurso da leitura produtiva acontece um movimento de reapropriação e reaproveitamento pessoal, ou seja, o texto opera como um instrumento, o qual leva o estudante a pensar o seu "eu" interior, como também a analisar, questionar e problematizar a sua condição como sujeito social. Certos temas como, por exemplo, o contextualizado em Negrinha, conto de Monteiro Lobato, podem acionar as lembranças de histórias correlacionadas, particularmente, à sua vivência. Todo esse processo de identificação ocorre, pois texto e aluno possuem um horizonte de expectativa. O texto desenha uma escritura composta de signos linguísticos pré-estruturados, que podem estar alinhados a um determinado gênero textual e apresentar, assim, traços próprios, específicos do gênero e o discente com um repertório constituído de elementos de outras leituras, lembranças de fatos vividos num ambiente pessoal e social e conhecimentos de mundo. Assim, do envolvimento do horizonte implícito de expectativa do texto com o horizonte de expectativa do educando acontece a leitura.

O processo de interiorização do aluno no ato de ler, a consciência libertadora conduzida pelo efeito da catarse remete ao conceito de "fruição estética", proposto por Jauss, pois "na atitude de fruição estética, o sujeito é libertado pelo imaginário de tudo aquilo que torna a realidade de sua vida cotidiana constrangedora”. (apud, JOUVE,2002, p.107). Embora o leitor/aluno não seja contemporâneo de Negrinha, ele fará inferências e criará hipóteses interpretativas para preencher as lacunas textuais. Em outras palavras, no percurso de fruição do conto de Monteiro Lobato:

A experiência da leitura logra libertá-lo das opressões e dos dilemas de sua práxis de vida, na medida em que o obriga a uma nova percepção das coisas. O horizonte de expectativa da literatura distingue-se daquele da práxis histórica pelo fato de não apenas conservar as experiências vividas, mas também antecipar possibilidades não concretizadas, expandir o espaço limitado do comportamento social rumo a novos desejos, pretensões e objetivos, abrindo, assim, novos caminhos para a experiência futura. (JAUSS, 1994, p.114).

Alinhados ao pensamento freiriano de letramento crítico, Green (1996; 1998) e Gee (1996) também abordam o conceito dimensional do letramento. De 
acordo com Green, (1998, p. 156) “a dimensão do letramento crítico é a base para assegurar que os indivíduos sejam não apenas capazes de participar de algumas práticas de letramento existentes, fazendo uso delas, mas que sejam também, de vários modos, capazes de transformar e produzir ativamente estas práticas". Gee (1996, p.16) afirma que "ser criticamente letrado significa ter habilidade em confrontar discursos e analisar como eles competem entre si no que diz respeito à relação de poder e interesse". Para este autor, o letramento está relacionado com as práticas sociais associadas com as diferentes culturas, levando em consideração a leitura e a escrita do texto de forma situada nas dimensões sociais, históricas e culturais.

De acordo com Kalantzis e Cope (2012), as abordagens críticas geralmente reconhecem os letramentos no plural, reconhecem as várias vozes que os aprendizes trazem para a sala de aula e as diferentes perspectivas que existem no mundo real dos textos. Essas abordagens críticas abrangem o aprendizado dos letramentos como ferramenta que permitem aos alunos a terem mais controle dos diversos sentidos produzidos em suas vidas, ao invés de torná-los alienados e excluídos por textos que não lhes são familiares. O letramento crítico aborda problematizações do mundo real que são de interesse dos estudantes e de suas comunidades. Kalantzis e Cope (2012) se coadunam a Freire em relação ao conceito de letramento como processo de ler e escrever sobre o mundo em que os cidadãos se tornam sujeitos ou agentes, não sendo objetos e pacientes do texto. Desta forma, o letramento crítico é um processo de aprendizagem em que os sujeitos produzem sentidos e são situados no mundo, para mudar esse mundo.

Segundo Kalantzis e Cope (2012), o objetivo dos letramentos críticos é ajudar os aprendizes a entenderem como o mundo é construído através das ações e valores das pessoas. Uma pessoa criticamente letrada identifica a relevância e o poder dos tópicos, analisa as evidências dos documentos, considera os diferentes pontos de vista, formula possíveis soluções para os problemas e talvez tenta solucioná-los, além de tirar suas próprias conclusões e elaborar argumentos que sustentem suas justificativas. 
Para os autores, as abordagens do letramento crítico têm como ênfase os textos que comunicam interesses e experiências relevantes aos alunos, textos que desafiam as questões sociais como, por exemplo, a discriminação. Por meio do pensamento crítico, os aprendizes veem o mundo de múltiplas formas e não assumem apenas os conceitos ou as ideias que estão dentro do texto. Para isso, o aluno é incentivado a questionar os textos e a interpretar os interesses humanos revelados nos textos.

\section{Ambiente da pesquisa e metodologia}

Adotamos a perspectiva interpretativista, pois realizamos uma atividade com a temática racismo embasada pelas teorias anteriormente mencionadas, abrangendo a dimensão epistemológica do ser cognoscente com a totalidade da vida em sociedade nas suas diversas esferas políticas, culturais, sociais e entre outras.

Segundo Freire (1993), a perspectiva epistemológica do tema gerador proporciona a interação do saber através do diálogo entre os indivíduos, promovendo a conscientização crítica e a reflexão da realidade social, cultural e histórica dos diferentes sujeitos. Portanto, a investigação do tema gerador, realizado por meio de uma metodologia conscientizadora e dialógica, possibilita a apreensão, inserção ou começa a inserir os homens numa forma crítica de pensarem seu mundo. Os temas existem nos homens, em suas relações com o mundo, ou seja, há uma relação entre a percepção que deles estejam tendo os homens e os temas geradores. Na prática problematizadora de Freire (1993), os educandos vão desenvolvendo a compreensão do mundo que thes aparece, assim como suas relações em uma realidade em transformação, em processo e não como uma realidade estática.

A proposta da discussão da temática do racismo surgiu a partir do desejo dos próprios discentes, os quais comentaram, durante uma conversa aberta, sobre 0 interesse em dialogar temas atuais. Para iniciar o debate, a classe compartilhou fatos relacionados aos variados tipos de preconceitos, que acabaram dando margem para um dos alunos mencionar um caso de 
intolerância racial presenciado por ele durante uma festa. O estudante relatou a cena de preconceito, ironias e palavras de ofensas, momentos angustiantes vivenciados por uma pessoa próxima.

Essa experiência testemunhal desencadeou um diálogo mais amplo sobre casos de racismo abordados pelos meios de comunicação. Além disso, debatemos os artigos $1^{\circ}$ e 20 da lei no 7.716, que pune a discriminação de cor e de raça. Assim, a temática do racismo consistiu em assunto para uma discussão que se estendeu por dois encontros.

Propomos a leitura do poema "Consciência e Atitude", que integra o livro Colecionador de pedras (2013) do escritor Sérgio Vaz para, assim, pensarmos a força do texto literário como elemento norteador de uma multiplicidade de vozes. Abordamos a integração entre a forma, a linguagem e a temática do racismo, ao refletir sobre os vocábulos e sobre os jogos de palavras inscritos no poema de Vaz.

Utilizamos recursos audiovisuais, como, por exemplo, vídeos de pessoas vítimas de racismo. Essa atividade com os vídeos possibilitou realizarmos uma atividade oral com perguntas abertas. Depois, realizamos a leitura compartilhada do conto Negrinha de Monteiro Lobato, o qual traz como pano de fundo a sociedade escravocrata dos anos iniciais do século XX no Brasil. Após a leitura crítica do conto, fizemos uma atividade de produção textual a qual será descrita a seguir, assim como os aspectos textuais e outras temáticas.

\section{Identidade e intolerância racial no conto Negrinha de Monteiro Lobato}

Em Negrinha há uma organização textual pré-estruturada, saberes e conhecimentos inscritos, os quais atuam como uma escrita de denúncia para os problemas sociais e políticos da época da escravidão. Nesse sentido, para pensar o letramento crítico é necessário entender que "textos têm efeitos sociais, construídos para dar uma versão "da verdade" [...] que textos não são neutros [...]". (JANKS, 2016, p.21). A compreensão da leitura se desenvolve nessa relação interacional entre texto e aluno, tendo em vista que ambos têm uma função diferente na concretização de sentido. 
Para a leitura do conto Negrinha, os alunos formaram duplas e trios. Nas atividades de pré-leitura, que antecedem a leitura do conto, os estudantes foram questionados sobre o que entendem sobre o racismo. Além disso, se já sofreram algum tipo de preconceito e como reagiram a esta atitude. As respostas foram variadas, pois, embora eles não tenham vivido experiência similar, já presenciaram atitudes preconceituosas com pessoas próximas a eles.

$\mathrm{Na}$ etapa das atividades de leitura, houve o questionamento sobre o título da obra de Monteiro Lobato. A personagem principal não tinha um nome, por isso era chamada por todos de negrinha. A primeira problemática, que emergiu durante a roda de leitura, foi o fato de a personagem ser chamada de negrinha, o que mostra a ausência de uma identidade, tendo em vista que o nome referese à identidade, denota a origem familiar e um reconhecimento social diante dos demais cidadãos.

A menina era órfã, tratada como um animal, um objeto sem valor qualquer largado pelos cantos da casa de D.Inácia e chamada pelas pessoas da casa de "pestinha, diabo, coruja, barata descascada, bruxa, pata choca, mosca morta, pinto gorado, sujeira, bisca, trapo, cachorrinha coisa ruim, lixo, [...]" (Lobato, 1956). Os alunos apontaram que esses apelidos e o qualificativo negrinha estariam atrelados a cor da pele da menina, um qualificativo de tom pejorativo ligado também a outros como, "magra, atrofiada". Negrinha é descrita, logo no início da narrativa, pelos seus olhos assustados, oprimidos, pois a criança servia para os da casa como um "saco de pancada", um objeto para diminuir as tensões, divertir e, para a senhora D.Inácia, relembrar o tempo da escravidão, matar a saudade, por isso conservava a menina como um remédio. Esse episódio da narrativa se apresenta como uma conjectura sobre o fato da dona da casa castigar com frequência a menina.

O corpo de negrinha era tatuado de sinais roxos, cicatrizes, vergões. Batiam nele os da casa, todos os dias, houvesse ou não motivo. A sua pobre carne exercia para os cascudos, cocres e beliscões a mesma atração que o íma exerce para o aço. Mão em cujos nós de dedos comichassem um cocre, era mão que se descarregaria dos fluidos em sua cabeça, de passagem. Coisa de rir, e ver a careta... (LOBATO, 1956). 
Para a atividade de pós-leitura foi proposta a elaboração de um final alternativo para o conto. Os alunos se reuniram em trios e duplas para produzirem os novos finais para o conto, os quais são apresentados a seguir:

Texto 1

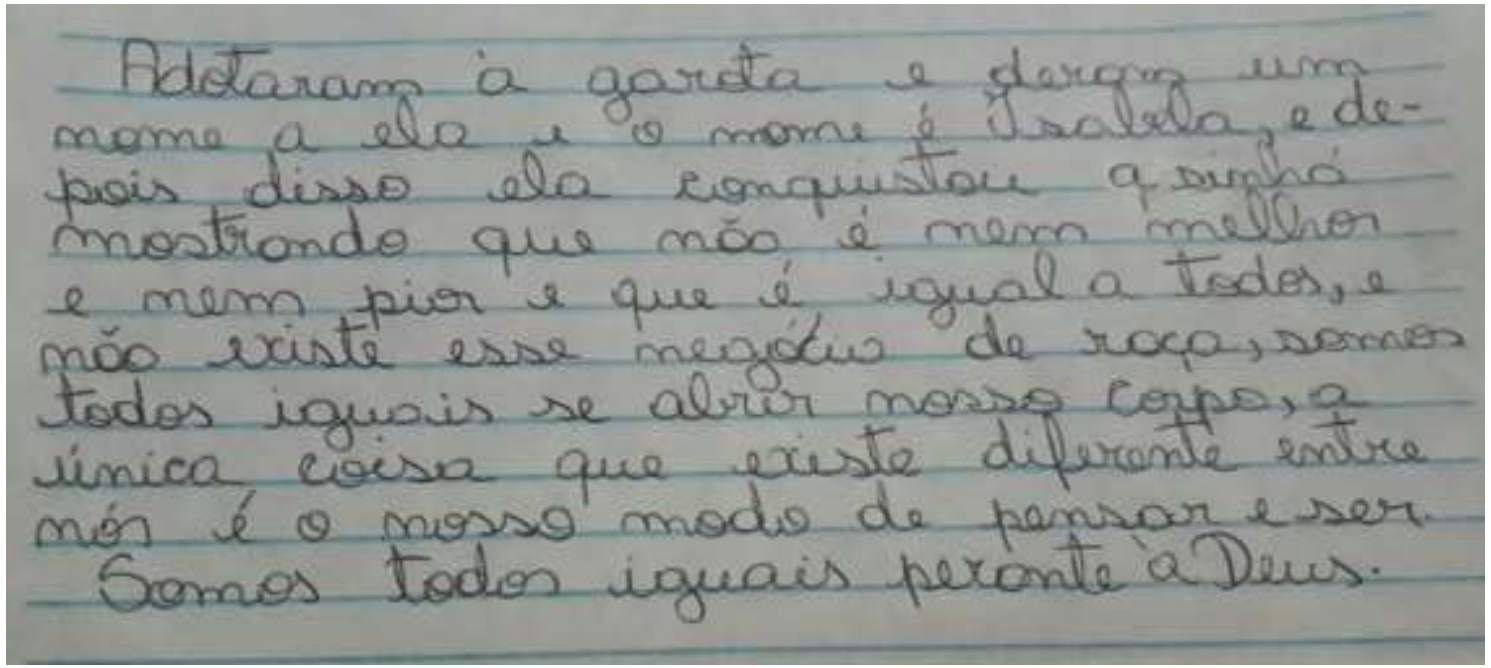

Texto 2

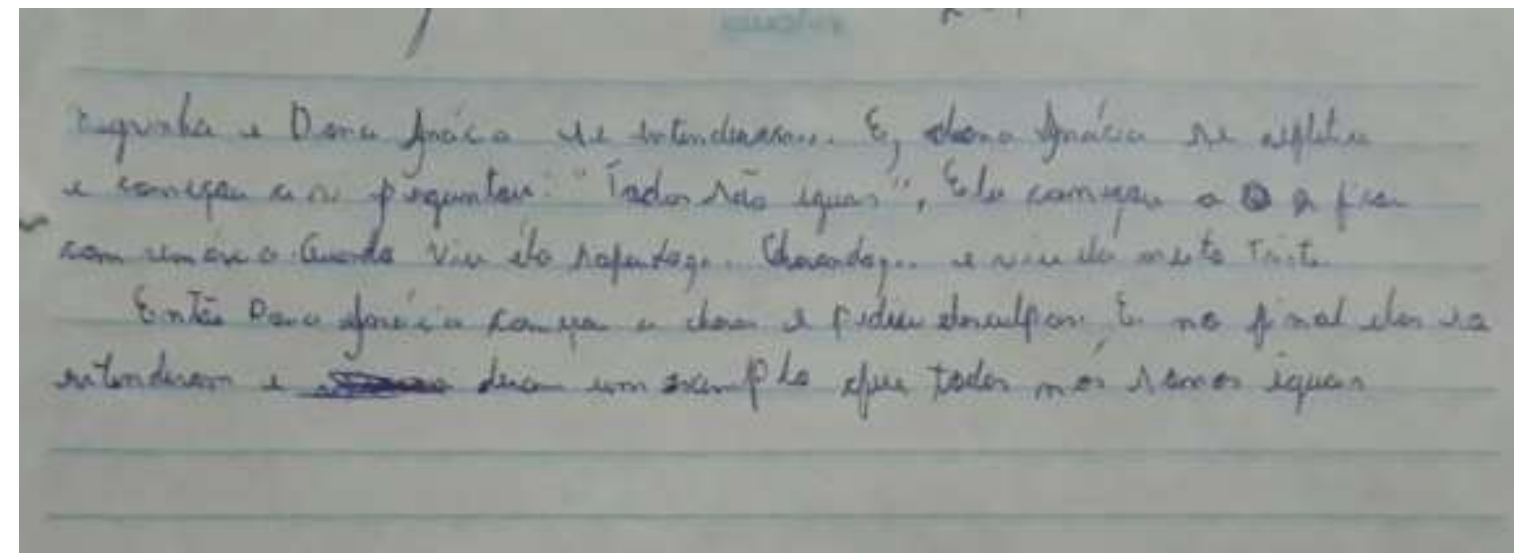

No Texto 1, nota-se a preocupação dos alunos em reconstruir a identidade da personagem. Nesse sentido, podem-se destacar três termos chaves que norteiam esse novo final: família, nome e raça humana. Ao imaginar a menina adotada por uma família, pensa-se na categoria família como um grupo, no qual a personagem iria se sentir amada, amparada e protegida, tendo em vista que, depois da morte da mãe Cesária a condição de negrinha, "que vivera-os pelos 
cantos escuros da cozinha, sobre farrapos de esteira e panos imundos. Sempre escondida, que a patroa não gostava de criança" (LOBATO, 1956), só piorou mais ainda, embora a menina estivesse amparada pelo amor e cuidados maternos. Agora a personagem tinha uma família, um lugar de origem, uma casa, apesar de não possuir nenhum laço consanguíneo, mas quem precisa de compatibilidade sanguínea quando o laço materno é construído pelo amor?

No entanto, a adoção da menina não constitui o fato principal nesse novo final, mas sim a atribuição do nome, que estabelece o ponto de partida, como se fosse o início da conquista de uma vida digna. Desse modo, o nome Isabela, que foi dado pela família, aponta a construção de uma nova identidade. Em outras palavras, a menina negrinha passa a ser reconhecida e chamada por um nome, o que denota um pertencimento àquela família. Além disso, o nome pode indicar uma história, uma personalidade e o apagamento de uma memória relacionada a momentos de dores físicas, dor na alma, desprezos e humilhações. Assim, ao nomeá-la de Isabela, seria esquecido todo sofrimento, traumas, mágoas e decepções, que a aprisionaram durante anos na casa da D.Inácia.

É possível observar o uso da expressão adverbial temporal "depois disso" e da escolha lexical "conquistou" na mesma sentença, anunciando uma nova fase de vida. Cabe ressaltar que o campo semântico do verbo "conquistar" associa-se ao ato de dominar pelas armas, de alcançar (algo), de receber (algo), de cativar, de atrair a consideração, enfim, de ser bem-sucedido e, todas essas acepções do verbo posicionam o sujeito em primeiro plano, apresentam um sujeito autônomo, dono da própria vida. Essa nova identidade criada pelos alunos para a personagem do conto de Monteiro Lobato será moldada pela vivência com a nova família.

O conceito de igualdade surge no texto 1 aliado à discussão sobre 0 conceito de raça como se observa em "e não existe esse negócio de raça, somos todos iguais", o qual parece se configurar como uma inserção dentro da narrativa, pois, ao fazer uma interrupção, os alunos expõem o ponto de vista mostrando que todos os seres humanos são iguais, não existindo, assim, raças, mas sim uma única concepção de raça, a raça humana. Na dicotomia igual $X$ 
diferente, a diferença é estabelecida fora do corpo material e se dá no âmbito mental, apontando para a dualidade corpo e mente e também para o aspecto individual em que cada sujeito é capaz de pensar e de ser por conta própria.

Por fim, revela-se um argumento relacionado à religião, pois no trecho "Somos todos iguais perante à Deus [sic]" os autores se utilizam do padrão religioso mais frequente para fazer valer a ideia de igualdade, visto que convivem em uma sociedade essencialmente cristã, que aponta a existência de Deus como dado inquestionável.

A palavra-chave, desse novo final apontado no texto 2, é "entendimento", tomado como "ajuste entre partes, faculdade de avaliar os seres e as coisas; julgamento". Os autores destacam no texto o entendimento entre as duas: Negrinha e D. Inácia. Isso após D. Inácia ter refletido, ter chegado à consciência e ter atingido o remorso. Visualiza-se, aqui, o processo essencialmente humano do pensamento ou da compreensão intelectual, faculdade negada, a princípio, aos animais irracionais. Nessa nova versão, nos é apresentada uma D. Inácia extremamente humana, capaz de refletir, atingir consciência de todo o mal que praticou contra a menina e sentir remorso. Isso faz com que peça desculpas e alcance o entendimento. A narrativa só nos mostra as atitudes de D. Inácia, porém fica subentendido que Negrinha aceitou as desculpas e promoveu 0 consenso.

Pode parecer, à primeira vista, um final ingênuo, um final "cor de rosa", mas a reafirmação final de que "deram um exemplo que todos nós somos iguais" faz com que reavaliemos essa ideia. Afinal, sim, temos a mesma natureza. Todos nós podemos errar e podemos nos arrepender dos erros que cometemos. Somos igualmente humanos.

\section{Considerações finais}

O letramento crítico pode possibilitar a leitura além da palavra, ou seja, a leitura do mundo. Permitindo, assim, que os aprendizes se tornem autores e leitores que refletem as problematizações abordadas de forma crítica, (re)construindos novos sentidos. Através da prática social da leitura e escrita, o 
educando lê o mundo considerando as suas próprias realidades, possibilitando o entendimento da realidade do outro e também na sua intervenção no mundo e para o mundo em uma perspectiva de justiça social. Na análise das produções escritas dos alunos, podemos perceber que os sentidos construídos estão em consonância com uma preocupação social. Através da atividade realizada no lócus escola, os alunos tiveram a oportunidade de atribuir um nome à personagem, de discutir sobre o racismo e de refletir sobre os problemas sociais ainda vigentes em nossa sociedade, os quais são abordados no contexto sóciohistórico em que a personagem Negrinha está inserida.

$\mathrm{O}$ ato de reescrever uma nova história para a Negrinha possibilitou aos educandos a prática do seu papel também de autor, o qual pode intervir e interagir com o texto. Ou seja, além de leitor, o aluno também se faz autor e re(cria) novas histórias, valorizando o seu papel de agente ativo no processo de construção do conhecimento.

Durante as atividades orais sobre a temática do racismo, os estudantes afirmaram que nunca sofreram atitudes de preconceito e/ou intolerância racial em algum momento de suas vidas. Apesar de não terem tido nenhuma experiência particular sobre a problemática em questão, os alunos já presenciaram tais atitudes racistas com pessoas conhecidas de seus círculos sociais. Sendo assim, através do princípio da alteridade, os estudantes se colocaram no lugar dessas pessoas que já sofreram discriminação racial e também da personagem Negrinha. A alteridade está presente tanto na prática social da leitura quanto na prática social da escrita, quando afirmam que somos todos iguais e por isso não deveríamos discriminar o outro por ter a cor de pele diferente. Logo, o letramento crítico pode contribuir para a prática social da leitura e escrita de forma reflexiva, crítica e conscientizadora, permeadas por princípios de alteridade, equidade e justiça social.

\section{REFERÊNCIAS}

BRYDON, D. Local Needs, Global Contexts: Learning New Literacies. In: MACIEL, R. F. e ARAÚJO, V. A. (Orgs). Formação de professores de línguas: ampliando perspectiva. Jundiaí: Paco Editora, 2011. 
FREIRE, P. A importância do ato de ler: em três artigos que se completam. São Paulo: Autores Associados: Cortez, 1989.

GEE, J. Social linguistics and literacies: ideology in discourses. $2^{a}$ ed. London: Taylor \& Francis, 1996.

GREEN, B. Subject-specific literacy and School learning: a focus on writing. Australia Journal of Education, 30(2): 1998. p. 156-69.

JANKS, H. Panorama sobre Letramento Crítico. In: -JESUS, D. M. de; CARBONIERI, D. (Org). Práticas de Multiletramentos e Letramento Crítico: outros sentidos para a sala de aula de línguas. Coleção: Novas perspectivas em Linguística aplicada. Vol. 47, Campinas, SP: Pontes Editores, 2016. p.21-39.

JAUSS, H. R. A história da literatura como provocação à teoria literária. Trad. Sérgio Tellaroli. São Paulo: Ática, 1994. p. 78.

JOUVE, V. A leitura; tradução Brigitte Hervot. - São Paulo: Editora UNESP, 2002.

KALANTZIS, M; Cope, B. Literacies. Cambridge University Press, New York, 2012.

LOBATO, M. Negrinha. São Paulo: Brasiliense, 1956. 